\title{
KAJIAN DAMPAK KEBIJAKAN UNITED STATES GENERALIZED SYSTEM OF PREFERENCE (US-GSP) 2015 TERHADAP EKSPOR PRODUK PERIKANAN INDONESIA KE USA
}

\section{The Impact of United States Generalized System of Preference (US-GSP) Toward Indonesia Fisheries Exports to USA}

\author{
"Rikrik Rahadian, Tajerin dan Zahri Nasution \\ Pusat Penelitian Sosial Ekonomi Kelautan dan Perikanan \\ Gedung Balitbang KP I Lt. 4 \\ Jalan Pasir Putih Nomor 1 Ancol Timur, Jakarta Utara, Indonesia \\ Telp: (021) 64711583 Fax: 64700924 \\ Diterima tanggal: 24 Agustus 2016 Diterima setelah perbaikan: 20 Oktober 2016 \\ Disetujui terbit: 3 Desember 2016 \\ "email: rikrik.rahadian@gmail.com
}

\begin{abstract}
ABSTRAK
Sejak pertamakali diperkenalkan pada tahun 1970-an, Generalized System of Preference (GSP) telah diterapkan oleh negara-negara maju seperti United States of America (USA), Jepang dan European Union (EU). Meskipun bertujuan serupa, yaitu mendorong serta memfasilitasi perdagangan bagi negara-negara berkembang, namun pada penerapannya di masing-masing negara terdapat perbedaan pengaturan GSP - terutama terkait perihal daftar beneficiaries (Negara Penerima Manfaat) serta produk yang memperoleh fasilitas GSP. Tulisan ini bertujuan untuk mengkaji kebijakan US-GSP 2015 serta menganalisis besaran dampak kebijakan tersebut terhadap kinerja ekspor produk Kelautan dan Perikanan (KP) Indonesia di pasar ekspor USA. Untuk tujuan tersebut maka telah dilakukan pengumpulan data perdagangan produk KP di USA pada tahun 2014 dari database TRAIN-UNCTAD dan simulasi dengan mempergunakan model SMART yang dikembangkan oleh World Integrated Trade Solutions (WITS). Hasil simulasi menunjukkan bahwa rejim US-GSP 2015 dapat dimanfaatkan untuk mendorong peningkatan kinerja ekspor produk perikanan Indonesia ke USA, terutama bagi komoditas sekunder/olahan. Oleh karena itu, kebijakan ekspor produk perikanan Indonesia harus difokuskan terhadap Industrialisasi sektor perikanan Indonesia.
\end{abstract}

Kata Kunci: generalized system of preference, USA, ekspor produk perikanan

\begin{abstract}
Ever since its introduction in the early 70's, the Generalized System of Preference (GSP) has been adopted and implemented by the developed countries such as United States of America (USA), Japan and the European Union (EU). Despite its only purpose - encouraging and facilitating trade for the developing countries - its implementation in each adopting country has been very customized especially concerning the beneficiary list and GSP product list. The purpose of this paper is to analyze the impacts of US-GSP 2015 implementation towards Indonesian Fisheries Export to the USA. The research was conducted using a SMART model - an economic model developed by the World Integrated Trade Solution (WITS) - to simulate the impacts of the trade policy using the TRAIN-UNCTAD database. The simulation showed that the 2015 US-GSP regime, if completely utilized by the Indonesian Exporters, could actually boost Indonesian Fisheries Exports to the USA, especially for the fish processing products. Therefore, fisheries product export policy should be focused on industrializing the Indonesian fishery sector.
\end{abstract}

Keywords: generalized system of preference, USA, fisheries product export 


\section{PENDAHULUAN}

Dalam hubungan dagang internasional dengan negara-negara maju, salah satu fasilitas kemudahan perdagangan yang disediakan bagi eksportir dari negara-negara berkembang adalah Generalized System of Preference (GSP). Pada prinsipnya, GSP adalah sebuah sistem tariff impor di negara-negara maju, yang dikhususkan bagi berbagai produk yang berasal dari negaranegara berkembang (Developing Countries/DC) dan terbelakang (Least-Developed Countries/LDC) (Pratomo, 2004). Awalnya fasilitas ini diajukan ke sidang WTO sebagai alat untuk mengatasi adanya ketimpangan dayasaing antara negara-negara maju dengan negara-negara berkembang, sehingga negara-negara berkembang diperkenankan menerima kemudahan berupa pengenaan tariff bea masuk lebih rendah daripada tariff normal - Most Favoured Nation (MFN) - dari negaranegara maju. Pada perkembangan selanjutnya, fasilitas ini juga mampu meningkatkan keterbukaan dan kesejahteraan negara-negara berkembang, seperti yang dialami oleh beberapa negara ASEAN - Indonesia, Thailand, Vietnam dan Malaysia - bahkan Republik Rakyat Tiongkok (RRT).

Sejak pertamakali diperkenalkan pada awal tahun 70-an, fasilitas GSP ini telah diaplikasikan oleh negara-negara maju seperti Amerika Serikat (USA), Uni-Eropa (EU) dan Jepang. Umumnya berbagai produk yang termasuk ke dalam daftar GSP ini akan dikenakan tariff $0 \%$. Selain itu, dalam GSP juga terdapat ketentuan terkait berbagai negara penerima fasilitas (Beneficiaries) serta produk apa saja yang diperkenankan memperoleh fasilitas GSP. Hal yang unik dari GSP adalah, meskipun wajib untuk diadopsi oleh negaranegara maju, akan tetapi memberikan kebebasan bagi masing-masing negara yang mengadopsi untuk menentukan beneficiaries serta product list sendiri.

Salah satu negara tujuan ekspor utama yang menerapkan fasilitas GSP dan telah dinikmati oleh Indonesia adalah USA. Pada bulan Juli setiap tahunnya, pemerintah USA menerbitkan sebuah Panduan GSP, berisikan daftar beneficiaries serta daftar produk apa saja yang memperoleh fasilitas GSP (Office of the United States Trade Representatives, 2015). Pada Juli 2015 yang lalu, panduan GSP di pasar USA terkini telah dipublikasi secara resmi. Setiap perubahan yang terjadi pada rejim GSP tersebut, tentunya akan secara langsung berpengaruh terhadap harga berbagai produk eligible yang diekspor oleh para beneficiaries ke USA, dan tentunya akan berdampak pada perubahan market share baik pada produk yang ada pada eligible list maupun pada produk-produk diluar list tersebut. Oleh karena itu, sebagai salah satu produk yang diekspor ke USA, Produk Kelautan dan Perikanan (KP) juga akan terpengaruh oleh perubahan yang terjadi pada rejim US-GSP 2015 ini.

Kajian dampak dari penerapan GSP maupun perubahan rejim GSP di negara-negara maju terhadap kinerja perdagangan dan performa perekonomian negara-negara berkembang telah cukup banyak dilakukan. Meskipun penelitian terkait manfaat dari GSP bagi negara berkembang pada kasus Uni Eropa menunjukkan bahwa secara empiris fasilitas ini dinilai berdampak sangat kecil terhadap perdagangan, bahkan tidak berdampak terhadap terjadinya diversifikasi perdagangan (Cirera, Foliano, \& Gasiorek, 2011), akan tetapi beberapa penelitian lain menunjukkan bahwa fasilitas GSP sangat berpengaruh bagi kinerja perdagangan dan performa ekonomi negaranegara berkembang. Salah satu contoh kasus adalah merosotnya kondisi perekonomian di Bangladesh akibat dari penurunan drastis kinerja ekspor pakaian jadi ke USA dan EU semenjak produk tersebut dikeluarkan dari GSP list di kedua negara tujuan ekspor tersebut (Kibria, Matin, \& Sharmin, 2016; Rashedul Islam \& Maruf, 2014). Sedangkan bagi negara maju sebagai tujuan ekspor, pencabutan fasilitas GSP berdampak terhadap menurunnya tingkat impor produk dari negara-negara berkembang, seperti pada kasus penurunan impor produk pertanian dan tekstil di USA ketika kedua produk tersebut dikeluarkan dari GSP list (Hakobyan, 2013).

Tujuan utama dari penulisan Karya Tulis Ilmiah ini adalah untuk menyediakan informasi terkait dampak dari penerapan kebijakan US-GSP 2015 terhadap performa ekspor produk Kelautan dan Perikanan (KP) Indonesia ke Pasar USA, melalui:

1. Kajian terkait rejim GSP yang diberlakukan di USA pada tahun 2015 ini;

2. Analisis dampak diberlakukannya US-GSP 2015 terhadap ekspor produk KP Indonesia ke pasar USA. 


\section{METODOLOGI}

\section{Metode Pengumpulan data}

Data yang akan dipergunakan sebagai bahan analisis dalam penelitian ini sepenuhnya berjenis data sekunder baik kuantitatif maupun kualitatif. Data kuantitatif berupa berbagai variabel perdagangan seperti nilai ekspor berbagai produk KP Indonesia dan negara-negara penerima manfaat GSP ke USA pada tahun 2014 serta besaran tarif bea masuk berbagai komoditas yang diekspor ke USA baik dari beneficiaries maupun nonbeneficiaries, diperoleh dari database TRAIN, yang dikelola oleh UNCTAD. Adapun data kualitatif yang diperlukan diperoleh melalui penelusuran pustaka terhadap berbagai dokumen yang terkait dengan US-GSP serta beragam penelitian terdahulu.

\section{Metode Analisis Data}

Dalam pelaksanaannya, analisis dilakukan dengan mengaplikasikan "SMART MODEL". Smart Model ini pada dasarnya merupakan pengembangan lebih lanjut dari "Model Produk Terdiferensiasi", yang dikembangkan oleh Verdoorn (1960) (Busse \& Großmann, 2004). Model ini pada awalnya diformulasi untuk tujuan analisis lebih dari sisi kepentingan negara konsumen (buyer) dari komoditas-komoditas atau produk-produk yang diimpor dari negara produsen. Namun dalam perkembangan selanjutnya, model tersebut disempurnakan oleh UNCTAD dan the World Bank sehingga dapat digunakan untuk analisis, tidak saja untuk kepentingan negara konsumen tetapi juga negara produsen yang melakukan kesepakatan perdagangan (ekonomi). Model ini dikenal dengan dikenal dengan sebutan "SMARTMODEL". Berikut ini dijelaskan masing-masing model tersebut.

\section{(1) Model Produk Terdiferensiasi}

"Model Produk Terdiferensiasi" (Differentiated Product Model) Verdoorn, meskipun telah berumur hampir 50 tahun, namun model ini merupakan model keseimbangan parsial yang tepat untuk menganalisis efek perdagangan dari kesepakatan kemitraan ekonomi yang di usulkan (Laird \& Yeats, 1986).

Model ini didasarkan pada asumsi-asumsi normal dari analisis keseimbangan parsial, seperti tidak adanya perubahan pada pendapatan atau nilai tukar uang, fungsi permintaan impor yang iso-elastis, dan elastisitas supply yang tidak terhingga. Asumsi terakhir tadi sering diterapkan dalam model-model perdagangan internasional, sangat rasional, karena Jepang, Amerika Serikat dan Uni Eropa adalah negara-negara besar dan total ekspor masing-masing negara ke Indonesia relatif kecil jika dibandingkan dengan total ekspor masing-masing negara ke dunia (Jammes \& Olarreaga, 2005).

Model Verdoorn menitikberatkan pada impor dari berbagai sumber, yaitu impor dari preference beneficiaries $\left(Q_{1}\right)$ dan dari non-beneficiaries $\left(Q_{2}\right)$. Model ini berdasarkan pada dua asumsi kunci. Pertama, fungsi permintaan dari the preference donor (Indonesia) untuk berbagai barang, adalah sebagai berikut:

$$
Q_{1}+Q_{2}=Q=\beta P_{1}^{\varepsilon \alpha 1} P_{2}^{\varepsilon \alpha 2}
$$

dimana $\mathrm{P}_{1}$ dan $\mathrm{P}_{2}$ adalah harga impor dari beneficiaries dan non-beneficiaries, $\alpha_{1}$ dan $\alpha_{2}$ adalah koefisien-koefisien share $\left(\alpha_{1}=Q_{1} /\left(Q_{1}+Q_{2}\right)\right.$, dan $\left.\alpha_{1}+\alpha_{1}=1\right), \beta$ adalah sebuah parameter dan $\varepsilon$ mewakili elastisitas permintaan impor. Dengan menggunakan elastisitas permintaan impor, data impor dapat dipergunakan tanpa harus mengandalkan data produksi domestik. Asumsi tersebut tidak hanya memudahkan, tetapi juga sangat diperlukan pada kasus Indonesia, karena data yang diperlukan tidak tersedia.

Kedua, elastisitas substitusi ( $\sigma)$ impor preferred dan non-preferred dapat dinyatakan sebagai berikut:

$$
Q_{1} / Q_{2}=\gamma\left[P_{1} / P_{2}\right]^{\sigma}
$$

$\mathrm{f}(\mathrm{t})$ dihilangkan hanya untuk impor yang preferred $\mathrm{Q}_{1}$ dan elastisitas supply adalah tak terhingga, maka harga impor beneficiaries $P_{1}$ berubah sebesar:

$$
\frac{\delta P_{1}}{P_{1}}=\frac{\delta t}{1+t}
$$

Maka total ekspansi impor dari sudut pandang negara-negara yang prefered sehubungan dengan perdagangan preferences dapat dinyatakan dalam persamaan sebagai berikut:

$$
\frac{\delta Q_{1}}{Q_{1}}=(\alpha 1 \varepsilon+(1-\alpha 1) \sigma)\left[\frac{\delta t}{1+t}\right]
$$

Reaksi berantai terjadi dalam dua tahap: pertama, tarif dikurangi hanya terhadap Q1, dan P1 turun, lalu konsumen mensubstitusi Q1 dengan Q2. Persamaan (4) dapat direkaulang dengan cara mensubstitusikan $\alpha 2$ untuk $\alpha 2$ : 


$$
\frac{\delta Q}{Q_{1}}=\left(\xi+\alpha_{2}(\sigma-\varepsilon)\right)\left(\frac{\delta t}{1+t}\right)
$$

Perubahan total pada preffered import dapat diuraikan menjadi Trade Creation (TC) dan Trade Diversion (TD). TC didefinisikan sebagai perubahan pada impor dari negara-negara beneficiaries $\left(Q_{1}\right)$ dan terdiri dari efek konsumsi, yang merupakan peningkatan pada konsumsi keseluruhan yang diakibatkan oleh penurunan harga, dan pengalihan produksi domestik. Efek ini dapat diturunkan dari sudut pandang negara prefered sebagai berikut:

$$
T C=Q_{1 \varepsilon}\left(\frac{\delta t}{1+t}\right)
$$

Selanjutnya, TD didefinisikan sebagai substitusi dari baik impor yang bersifat prefered maupun non-prefered sebagai akibat dari peniadaan tarif yang preferential:

$$
T D=Q_{1 \alpha 2}(\sigma-\varepsilon)\left(\frac{\delta t}{1+t}\right)
$$

Terakhir, perubahan yang diharapkan pada Penerimaan Cukai/Custom Revenue (CR) adalah sama dengan jumlah kewajiban impor bagi impor dari negara-negara yang prefered $Q_{1}$, yang sekarang sudah tidak termasuk lagi dalam tarif impor, dan penggantian impor-impor dari negaranegara yang non-prefered (TD) dikalikan dengan tarif impor:

$$
\delta C R=\left(Q_{1}+T D\right) t
$$

Estimasi TC dan TD dan perubahan pada pendapatan cukai dilakukan pada Harmonised System(HS) levelempat digit. Pada tingkataggregasi tersebut, Tabel HS terdiri dari sekitar 1,240 barang. Pendekatan disaggregasi dengan tingkat ketelitian seperti ini menjamin estimasi efek perdagangan yang lebih akurat, karena, pada kasus adanya TD, menyertakan kompetisi dari berbagai negara pada level yang tepat. Selain itu, hal ini memungkinkan identifikasi berbagai komoditas yang kemungkinan besar akan terpengaruh oleh EPA. Berbagai tarif dan data perdagangan diperolah dari berbagai narasumber seperti Trade Analysis and Information System (TRAINS) UNCTAD, database terintegrasi WTO, database COMTRADE, BPS, DEPERDAG dan berbagai sumber data lainnya.

Seperti dapat dilihat dari persamaan (6) dan (7), estimasi TC \& TD pada model produk yang terdiferensiasi memerlukan estimasi elastisitas baik permintaan impor maupun substitusi. Sayangnya estimasi handal dari kedua elastisitas tersebut bagi Indonesia pada tingkat HS 4 digit tidak tersedia. Untuk mengatasinya, maka nilai-nilai elastisitas tersebut ditentukan berdasarkan asumsi (yang didekati dari beberapa hasil riset yang relevan). Secara spesifik, untuk memperoleh estimasi elastisitas tersebut dibuat tiga buah skenario, yaitu skenario rendah, menengah dan tinggi yang masing-masing skenario berbeda pada angka elastisitas yang diasumsikan nantinya.

\section{(2) SMART MODEL}

Partial equilibrium SMART model merupakan pengembangan lebih lanjut dari Differentiated Product Model, yang dikembangkan oleh UNCTAD dan the World Bank sejak tahun 1980an terutama untuk menilai dampak dari GATT rounds. Terkait dengan tujuan yang ingin dicapai dari kajian ini, SMART Model dalam hal ini dipandang lebih tepat dibandingkan dengan pendahulunya (Differentiated Product Model), karena mampu menganalisis efek perdagangan bilateral antara negara-negara maju dan berkembang, tanpa mengalami bias terhadap negara maju (Superior Party) seperti yang terjadi dengan menggunakan Differentiated Product Model.

The SMART model terdapat dalam WITS software, penggunaan SMART dapat mengevaluasi dan melihat konsekuensi dan dampak dari perubahan kebijakan perdagangan (dalam ukuran tarif) dalam beberapa variabel-variabel yang terkait dengan konsekuensi kerjasama bilateral, yaitu: Efek Trade Creation (TC), Efek Trade Diversion (TD), dan Agregasi TC dan TD. Selain itu, lebih lanjut lagi, SMART Model juga akan dapat menunjukkan variabel-variabel yang berkaitan dengan dampak dari kerjasama bilateral, yaitu: Variasi penerimaan tariff dan Perubahan dalam Surplus (Konsumen, Produsen dan Nasional).

The SMART mode/memiliki 3 jenis elastisitas:

(i) Supply elasticities, yang mana dapat bernilai (=99). Hal ini berarti bahwa peningkatan permintaan untuk barang tertentu akan selalu dicocokan oleh produsen dan eksportir dari barang tersebut, tanpa adanya dampak pada harga barang tersebut.

(ii) Import substitution elasticities barang yang sama dari Negara yang berbeda imperfectly substitutable. Dalam SMART, import 
substitution elasticity bernilai 1.5 untuk setiap barang

(iii) Import demand elasticity mengukur respon permintaan dalam beralih ke harga import. DalamSMART, import demand elasticity berdasarkan pada "price elasticities in international trade".

Asumsi penting lainnya dari model ini adalah perfect competition, dimana dalam pemotongan tariff secara penuh dicerminkan dalam harga yang dibayarkan konsumen.

(3) Model Matematika

\section{- Trade Creation (TC)}

Trade creation menangkap aspek perkembangan perdagangan (liberalisasi) sebagai contoh Free Trade Area. Derivasi dimulai dari fungsi import demand dan export supply:

Fungsi permintaan impor yang disederhanakan untuk negara $j$ dari negara $k$ untuk komoditas $t$ :

$$
M_{t j k}=f\left(Y_{j}, P_{t j}, P_{i k}\right) \text {. }
$$

Fungsi supply ekspor untuk komoditas $i$ dari negara $k$ dapat disederhanakan seperti berikut:

$$
X_{i j k}=f\left(P_{i j k}\right)
$$

Keseimbangan perdagangan antara kedua Negara adalah persamaan keseimbangan parsial standar:

$$
M_{t j k}=X_{i j k}
$$

Dalam lingkungan perdagangan bebas, harga domestik komoditas $i$ di negara $j$ dari negara $k$ akan berubah seiring dengan perubahan tarif seperti:

$$
P_{i j k}=P_{i k j}\left(1+t_{t j k}\right)
$$

Untuk menurunkan formula TC, sesuai dengan Laird dan Yeats (1986), persamaan (12) di atas diturunkan secara total untuk memperoleh:

$$
\mathrm{dP}_{\mathrm{ijk}}=P_{\mathrm{ikj}} d \mathrm{t}_{\mathrm{ijk}}+\left(1+\mathrm{t}_{\mathrm{ijk}}\right) d P_{\mathrm{ikj}}
$$

Persamaan (12) dan (13) disubstitusikan untuk memperoleh persamaan elastisitas permintaan impor untuk memperoleh:

$$
\frac{d M_{t j k}}{M_{i j k}}=\eta_{i}^{m}\left(\frac{d t_{t j k}}{\left(1+t_{i j k}\right)}+\frac{d P_{t j k}}{P_{i k j}}\right)
$$

Persamaan identitas (11), $\frac{d M_{i j k}}{M_{i j k}}=\frac{d X_{i k j}}{X_{i k j}} \quad$ dapat dipergunakan untuk menurunkan persamaan elastisitas supply ekspor berikut:

$$
\frac{d P_{i k j}}{P_{i k j}}=\frac{1}{\gamma_{t}^{e}} \frac{d M_{i j k}}{M_{i j k}}
$$

yang jika digunakan pada Persamaan (14), akan memungkinkan untuk memperhitungkan efek TC. Dari Persamaan (11) efek TC sama dengan pertumbuhan ekspor negara $k$ atas komoditas $i$ ke negara $j$ :

$$
T C_{i j k}=M_{i j k} \eta_{i}^{m} \frac{d t_{i j k}}{\left(\left(1+t_{i j k}\right)\left(1-\eta_{i}^{m} / \gamma_{i}^{e}\right)\right)}
$$

Jika $\quad \gamma_{i}^{e}=\infty$, maka persamaan (15) dapat disederhanakan sebagai berikut:

$$
T C_{i j k}=\eta_{i}^{m} M_{i j k} \frac{\left(1+t_{i j k}^{1}\right)-\left(1+t_{i j k}^{0}\right)}{\left(1+t_{i j k}^{0}\right)}
$$

Dimana $\mathrm{TC}_{\mathrm{ijk}}$ adalah penjumlahan dari TC dalam U\$ juta atas komoditas $i$ yang terpengaruh oleh perubahan tariff dan $\eta_{i}^{m}$ adalah elastisitas permintaan impor untuk komoditas $i$ pada negara pengimpor dari mitra dagang yang relevan. $\mathrm{M}_{\mathrm{ijk}}$ adalah tingkat permintaan impor saat ini untuk komoditas i. $t_{i j k}^{0}$ dan $t_{i j k}^{1}$ mewakili tarif awal dan akhir bagi komoditas $i$. Dengan demikian TC sangat dipengaruhi oleh tingkat impor sekarang, elastisitas permintaan impor, dan perubahan relatif dari tarif.

\section{- Trade Diversion}

Berlawanan dengan trade creation, trade diversion memiliki persamaan sebagai berikut:

$$
\sigma_{M}=\frac{\Delta\left(\sum_{k} M_{i j k} / \sum_{K} M_{i j K}\right) /\left(\sum_{k} M_{i j k} / \sum_{K} M_{i j K}\right)}{\Delta\left(P_{i j k} / P_{i j K}\right) /\left(P_{i j k} / P_{i j K}\right)} \ldots
$$

dimana $\mathrm{k}$ menunjukan impor dari negara mitra, dan $K$ dari rest of the world (ROW). Persamaan (18) tersebut selanjutnya dapat diperluas, dan melalui substitusi dan pengaturan ulang dapat dipergunakan untuk memperoleh persamaan TD, sebagai berikut:

$$
T D_{i j k}=\frac{M_{i j k}}{\sum_{k} M_{i j k}} \frac{\sum_{k} M_{i j k} \sum_{K} M_{i j k} \frac{\Delta\left(P_{i j k} / P_{i j k}\right)}{P_{i j k} / P_{i K}} \sigma_{M}+\sum_{K} M_{i j K}+\sum_{k} M_{i j k} \frac{\Delta\left(P_{i j k} / P_{i K K}\right)}{P_{i j k} / P_{i j K}} \sigma_{M}}{. .}
$$


Persamaan (19) dapat disederhanakan khusus untuk kasus EPA. Termin pergerakan harga relatif pda persamaan seperti ditulis oleh Laird dan Yeats (1986) menangkap pergerakan akibat perubahan tarif atau insiden distorsi non-tarif bagi negara mitra dan ROW. Oleh karenanya perdagangan beralih ke negara mitra EPA, TDEPA dapat ditangkap dengan cara mereduksi persamaan (10) sebagai berikut:

$$
T D^{E P A}=\frac{M^{E U} M^{R O W}\left(\frac{1+t_{E U}^{1}}{1+t_{E U}^{0}}-1\right) \sigma_{M}}{M^{E U}+M^{R O W}+M^{E U}\left(\frac{1+t_{E U}^{1}}{1+t_{E U}^{0}}-1\right) \sigma_{M}} \cdots
$$

Persamaan (20) menunjukkan tambahan impor negara mitra kepada mitra EPA nya sebagai hasil dari TC.

\section{HASIL DAN PEMBAHASAN}

\section{US-GSP 2015}

Hasil study pustaka terhadap berbagai dokumen terkait rejim GSP USA 2015 telah memberikan beberapa informasi kunci yang dapat dirangkum sebagai berikut:

- Rejim US-GSP 2015 - terkait produk KP relatif tidak mengalami perbedaan dengan rejim GSP USA 2012 (Office of the United States Trade Representatives, 2015; Office of the United States Trade Representatives, 2012);

- Di pasar USA, beneficiaries digolongkan menjadi kelompok $A$, yang umumnya terdiri dari negara-negara berkembang (DC), dan
$A+(L D C)$, yang umumnya negara-negara kurang berkembang (LDC) (Office of the United States Trade Representatives, 2015);

- Hingga 2015 ini, Indonesia masih merupakan salah satu dari 120 negara beneficiaries yang tergolong kedalam kelompok $\mathrm{A}$ di pasar USA (Office of the United States Trade Representatives, 2015);

- Berdasarkan daftar produk US-GSP yang dipublikasikan pada tahun 2012 dan berlaku hingga saat ini, terdapat 34 Produk Perikanan Indonesia yang dapat memanfaatkan fasilitas GSP ini (Office of the United States Trade Representatives, 2012);

- Dari ke-34 produk yang berada pada daftar tersebut, beberapa produk perikanan unggulan Indonesia, seperti Udang dan Tuna, tidak termasuk ke dalam daftar produk penerima fasilitas GSP di pasar USA (Office of the United States Trade Representatives, 2012).

\section{Perkembangan Ekspor Produk KP Indonesia ke USA Periode 2012-2014}

Sepanjang periode 2010-2014, ekspor produk KP Indonesia ke USA mengalami kecenderungan peningkatan. Nilai ekspor Kelautan dan Perikanan (KP) Indonesia ke USA mengalami peningkatan pesat sejak tahun 2010 yang lalu. Seperti ditunjukkan pada Gambar 1, terdapat kecenderungan pertumbuhan nilai ekspor produk KP Indonesia ke USA sebesar lebih dari dua kali lipat, dari total senilai U\$817.948.156 pada tahun 2010 menjadi senilai U\$ 1.798.285.130 pada tahun 2014.

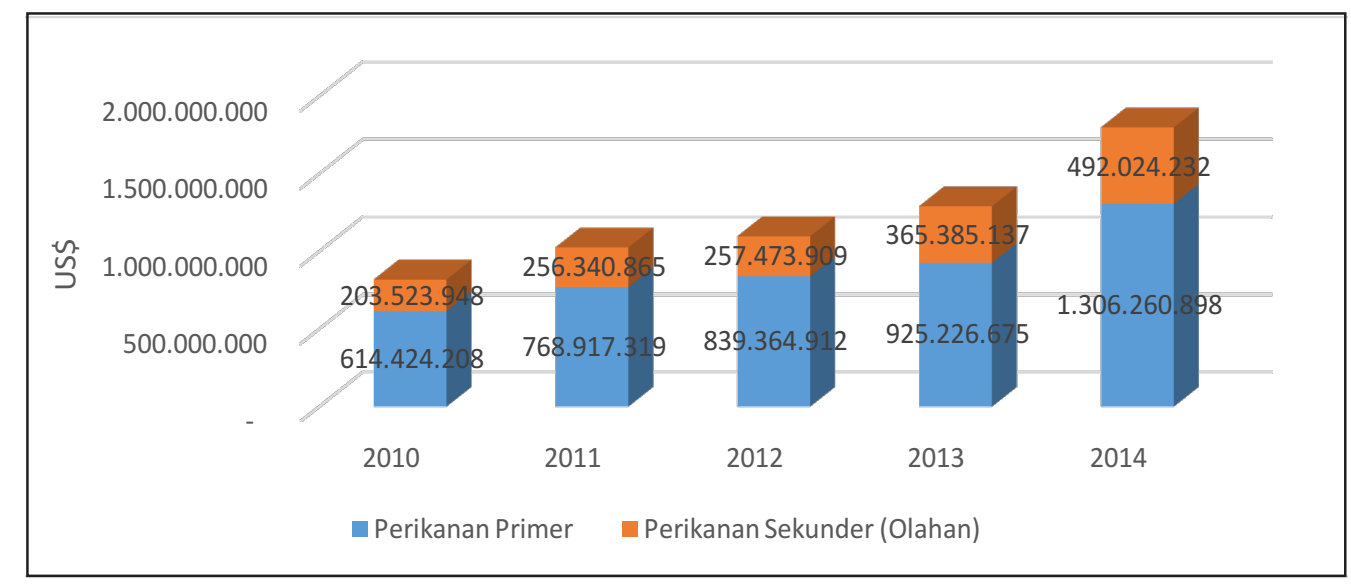

Gambar 1. Perkembangan Nilai Ekspor Produk KP Indonesia ke USA, 2010-2014

Figure 1. Indonesian Fisheries Product Export Value to USA, 2010-2014

Sumber: Olahan Database TRAINS, WITS/Source: TRAINS Database, WITS 
Gambar 1 menunjukkan adanya kecenderungan pertumbuhan total nilai ekspor perikanan Indonesia ke USA. Meskipun sempat terjadi perlambatan dari pertumbuhan sebesar $25,3 \%$ pada $2010-2011$ ke $7 \%$ pada periode 2011-2012, akan tetapi pertumbuhan pada periode selanjutnya kembali ke trend percepatan pertumbuhan. Terjadi lonjakan pertumbuhan total ekspor produk KP yang cukup tinggi ke angka $17,7 \%$ pada periode 2012-2013 diikuti dengan pertumbuhan yang jauh lebih tinggi ke angka $39,3 \%$ pada periode $2013-2014$.

Pertumbuhan dengan pola serupa juga terjadi pada ekspor produk KP Primer Indonesia ke USA. Pertumbuhan mengalami perlambatan dari angka 26,0\% pada periode 2010-2011 ke angka $9,2 \%$ pada periode $2011-2012$, dan diikuti dengan kecenderungan percepatan pertumbuhan pada periode berikutnya. Pertumbuhan nilai ekspor produk KP primer mencapai angka 10,2\% pada periode 2012-2013, dan diikuti oleh lonjakan tajam ke angka 41,2\% pada periode 2013-2014.

Pada ekspor produk KP sekunder, terjadi pola pertumbuhan yang tergolong fluktuatif. Pertumbuhan sebesar $25 \%$ pada periode 2010-2011 diikuti perlambatan yang sangat tajam ke angka 0,4\% pada periode 2011-2012. Meskipun kembali terjadi percepatan pertumbuhan ke angka $41,9 \%$ pada periode $2012-2013$, akan tetapi diikuti dengan perlambatan ke angka $34,7 \%$ pada periode 2013-2014.

Gambar 2 menunjukkan terjadinya fenomena peralihan ekspor produk KP Indonesia ke USA, dari produk primer ke produk sekunder. Secara rata-rata, pada periode pasca 2012 , pertumbuhan ekspor yang dialami produk KP sekunder adalah sebesar $38,3 \%$. Angka tersebut jauh melebihi angka pertumbuhan ekspor produk KP primer yang hanya mencapai $25,7 \%$, bahkan berada di atas rata-rata total produk KP (28\%). Sehingga dapat tidak salah apabila dikatakan bahwa lonjakan pertumbuhan ekspor produk KP Indonesia ke USA, yang terjadi pasca 2012, tersebut didorong oleh terjadinya peningkatan pertumbuhan ekspor produk KP olahan.

Peralihan ekspor produk KP Indonesia ke USA dari primer ke sekunder seperti yang telah disampaikan di atas masih jauh dari dari ideal. Dari sisi komposisi, terlihat bahwa produk primer masih tetap mendominasi ekspor produk KP Indonesia ke USA. Seperti dapat diamati pada gambar 3, terlihat betapa angka share ekspor produk KP primer Indonesia ke USA pra 2012 tidak bergeming dari angka $75 \%$. Meskipun terjadi perubahan pada pasca 2012, akan tetapi share ekspor produk KP primer Indonesia ke USA masih tetap cukup tinggi pada angka $72 \%$ dan $73 \%$ (Gambar 3 ).

Perubahan seperti yang dicermati pada gambar 3 tersebut berkaitan dengan diberlakukannya rejim GSP USA 2012. Pada rejim GSP USA 2012, terdapat kecenderungan pemberian fasilitas GSP, dengan tarif bea masuk sebesar $0 \%$, atas produk-produk KP Olahan. Seperti telah disampaikan pada bagian terdahulu, daftar produk GSP 2012 tersebut masih diberlakukan hingga rejim GSP USA 2015 ini.

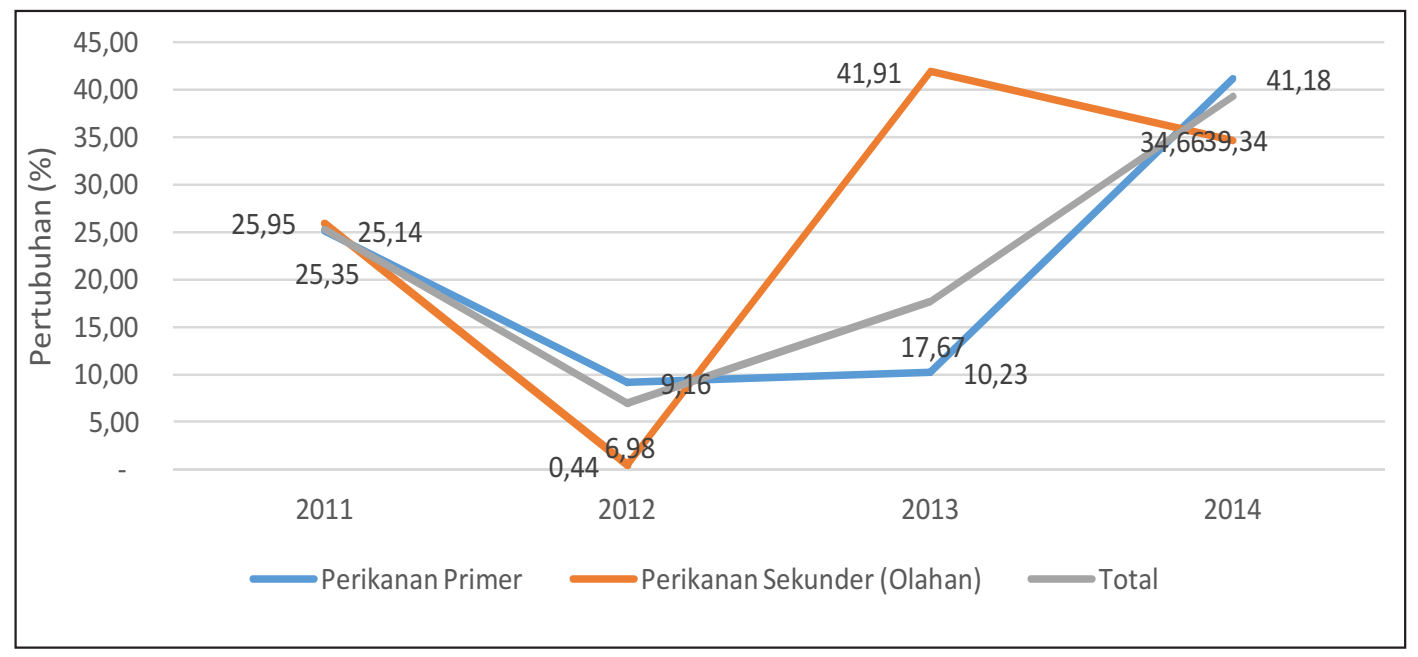

Gambar 2. Pertumbuhan Nilai Ekspor Produksi KP Indonesia ke USA, 2010-2014

Figure 2. Growth of Indonesian Fisheries Product Export to USA, 2010-2014

Sumber: Olahan Database TRAINS, WITS/Source: TRAINS Database, WITS 


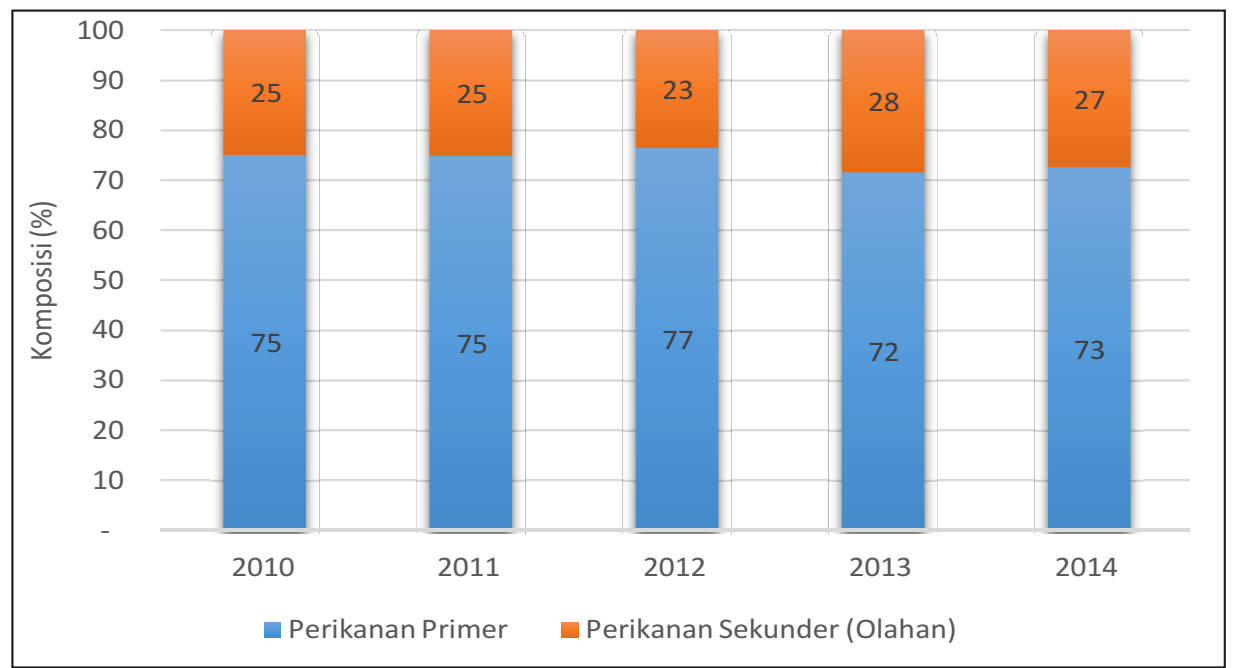

Gambar 3. Perkembangan Komposisi Ekspor Produk KP Indonesia ke USA, 2010-2014 Figure 3. The Composition of Indonesian Fisheries Export to USA, 2010-2014

Sumber: Olahan Database TRAINS, WITS/Source: TRAINS Database, WITS

\section{Hasil Simulasi Dampak Penerapan Rejim GSP 2015 di USA}

Untuk mengetahui dampak dari penerapan rejim GSP USA 2015, maka telah dilakukan sebuah simulasi dengan menggunakan model SMART yang dikembangkan oleh WITS-UNCTAD. Tabel 1 menunjukkan hasil simulasi penerapan GSP 2015 USA terhadap ekspor Produk KP Indonesia ke USA. Penerapan GSP berdasarkan rejim tahun 2015 di pasar USA memberikan potensi peningkatan ekspor bagi produk Perikanan Indonesia sebesar U\$ 152.311.680 - dimana senilai U\$73.710.364 berupa Produk KP Primer dan senilai U\$ 78.601.316 berupa produk KP Olahan. Nilai peningkatan ekspor KP tersebut menempatkan Indonesia sebapai top 3 gainers negara eksportir produk KP ke USA di bawah Thailand dan Malaysia.

Hal yang patut dicermati dari hasil simulasi tersebut adalah bahwa meskipun secara total Indonesia berhasil menempati urutan ketiga, akan tetapi apabila dilihat dari sisi peningkatan ekspor produk KP olahan ke USA, maka Indonesia hanya menempati urutan ke-8 di bawah Argentina. Indonesia bahkan kalah cukup jauh di

Tabel 1. Hasil Simulasi Penerapan GSP 2015 di USA.

Table 1. US-GSP 2015 Simulation Results.

\begin{tabular}{|c|c|c|c|c|}
\hline \multirow{2}{*}{ No. } & \multirow{2}{*}{$\begin{array}{l}\text { Negaral } \\
\text { Countries }\end{array}$} & \multicolumn{3}{|c|}{$\begin{array}{c}\text { Nilai Dampak Ekspor Produk Perikanan/ } \\
\text { Fisheries Product Export Impact Value (U\$) }\end{array}$} \\
\hline & & $\begin{array}{l}\text { Produk Primerl } \\
\text { Primary Products }\end{array}$ & $\begin{array}{l}\text { Produk Sekunder (Olahan)I } \\
\text { Manufactured Products }\end{array}$ & $\begin{array}{l}\text { Nilai Total/ } \\
\text { Total Value }\end{array}$ \\
\hline 1 & Thailand & 82.946 .173 & 103.178 .075 & 186.124 .248 \\
\hline 2 & Malaysia & 47.173 .322 & 114.075 .237 & 161.248 .559 \\
\hline 3 & Indonesia & 73.710 .364 & 78.601 .316 & 152.311 .680 \\
\hline 4 & Philippines & - & 110.016 .164 & 110.016 .164 \\
\hline 5 & Argentina & 23.850 .254 & 81.756.199 & 105.606 .453 \\
\hline 6 & Myanmar & 19.489 .368 & 83.055 .908 & 102.545 .276 \\
\hline 7 & Ecuador & 1 & 86.179 .131 & 86.179.132 \\
\hline 8 & China & 16.547 .285 & 67.414 .126 & 83.961 .411 \\
\hline 9 & India & - & 82.429 .763 & 82.429 .763 \\
\hline 10 & Fiji & - & 25.254 .984 & 25.254 .984 \\
\hline 11 & Venezuela & 11.169 .473 & 4.357 & 11.173 .830 \\
\hline 12 & Bangladesh & - & 10.300.391 & 10.300.391 \\
\hline 13 & Turkey & - & 2.725 .145 & 2.725 .145 \\
\hline
\end{tabular}

Sumber: Olahan SMART Model, WITS/Source: SMART Model, WITS 
sisi peningkatan ekspor produk KP olahan ketika dibandingkan dengan empat tetangga pesaing di ASEAN - Malaysia yang menempati posisi pertama, Philippines di posisi kedua, Thailand di posisi ketiga dan Myanmar di posisi kelima. Hal tersebut mengindikasikan betapa Indonesia sangat tertinggal oleh negara-negara pesaingnya dalam mengembangkan produk KP olahan, sehingga respon terhadap perubahan rejim GSP USA 2015 tersebut menjadi kurang tinggi.

\section{KESIMPULAN DAN IMPLIKASI KEBIJAKAN}

\section{Kesimpulan}

Secara ringkas, kajian yang dilakukan telah menghasilkan beberapa kesimpulan seperti di bawah berikut:

Terdapat kecenderungan pertumbuhan nilai total ekspor produk perikanan Indonesia ke USA sejak periode 2012-2014, seiring dengan diberlakukannya kebijakan US-GSP 2012;

Terdapat kecenderungan peningkatan pangsa ekspor produk KP olahan ke pasar USA - meskipun kecil - pada periode 2012-2014. Hal ini nampaknya terkait dengan adanya insentif pada US-GSP 2012 yang cenderung memberikan kemudahan bagi produk KP olahan dibandingkan produk KP primer;

Berbagai produk perikanan unggulan Indonesia, seperti Udang dan Tuna, tidak termasuk ke dalam daftar produk penerima fasilitas GSP;

Simulasi yang dilakukan menunjukkan bahwa rejim US-GSP 2015, akan dapat mendorong peningkatan kinerja ekspor produk KP Indonesia ke USA, terutama untuk komoditas sekunder/olahan.

Mengingat potensi manfaatnya yang sangat baik dalam mendorong peningkatan ekspor Produk Sekunder/Olahan Ikan ke pasar USA, maka kebijakan GSP USA 2015 ini perlu disikapi melalui beberapa kebijakan sebagai berikut:

- Peningkatan kesadaran para eksportir produk olehan perikanan terkait fasilitas GSP, agar para eksportir yang sudah ada sekarang mampu memanfaatkan fasilitas tersebut secara maksimal di jangka pendek;

- Merubah mindset ekspor ke USA, mengurangi ketergantungan terhadap ekspor komoditas primer dan beralih ke eksor produk sekunder/ olahan, untuk mendorong ekspor produk perikanan Indonesia ke Indonesia di jangka panjang;

- Mempercepat perkembangan pengolah produk perikanan - terutama di Indonesia Timur - untuk mendorong peningkatan produksi olahan perikanan di jangka panjang.

\section{Implikasi Kebijakan}

Beberapa program yang harus disiapkan oleh KKP untuk menyikapi kebijakan perdagangan USA - melalui rejim US-GSP 2015 - adalah:

- Kebijakan sosialisasi mengenai kelengkapan dokumen-dokumen ekspor produk-produk perikanan yang termasuk ke dalam daftar GSP USA;

- Melanjutkan dan mengintensifkan kebijakan industrialisasi produk perikanan;

- Membangun Indonesia Timur sebagai pusat Industri produk olahan perikanan Indonesia;

- Mempersiapkan jalur logistik dan ekspor ikan nasional;

- Mempermudah permodalan bagi pengusaha pengolah produk perikanan kecil dan menengah di Indonesia Timur.

\section{UCAPAN TERIMA KASIH}

Ucapan terimakasih sebesar-besarnya kami tujukan bagi Kepala Pusat Penelitian Sosial Ekonomi Kelautan dan Perikanan (PPSEKP) yang telah memberikan kesempatan penulis untuk melakukan kajian ini. Selain itu kami juga mengucapkan terimakasih kepada tim penyunting Jurnal Kebijakan Sosial Ekonomi Kelautan dan Perikanan atas kerjasama serta masukan yang telah diberikan sepanjang proses perbaikan tulisan ini.

\section{DAFTAR PUSTAKA}

Busse, M., \& Großmann, H. (2004). Assessing the Impact of ACP/EU Economic Partnership Agreement on West African countries. HWWA Discussion Paper.

Cirera, X., Foliano, F., \& Gasiorek, M. (2011). The Impact of GSP Preferences on Developing Countries' Exports in the European Union: Bilateral Gravity Modelling at the Product Level. Economics Department Working Paper Series, No. 27, University of Sussex.

Hakobyan, S. (2013). GSP Expiration and Declining Exports From Developing Countries. Working Paper, Fordham University, December. 
Jammes, O., \& Olarreaga, M. (2005). Explaining SMART and GSIM. The World Bank.

Kibria, A. M., Matin, S., \& Sharmin, R. (2016). Impact of GSP Cut: The Case of RMG Sector in Bangladesh. World Journal of Social Sciences, Vol. 6, No. 1, March Issue, 20-31.

Laird, S., \& Yeats, A. (1986). The UNCTAD Trade Policy Simulation Model. Geneva: UNCTAD.

Office of the United States Trade Representatives. (2012). GSP Eligible: All BDCs. Washington, D.C.: Office of the United States Trade Representatives.

Office of the United States Trade Representatives. (2015). GSP - Eligible Agricultural Product. Washington, D.C.: Office of the United States Trade Representatives.
Office of the United States Trade Representatives. (2015). GSP GUIDE BOOK. Washington, D.C.: Office of the United States Trade Representatives.

Pratomo, W. (2004). Teori Kerjasama Perdagangan Internasional. Dalam S. Arifin, D. E. RAE, \& C. P. Joseph., Kerja Sama Perdagangan Internasional: Peluang dan Tantangan Bagi Indonesia. Jakarta: PT. Gramedia.

Rashedul Islam, M., \& Maruf, K. N. (2014). Impact of EU GSP Facilities On Export Growth Of Bangladesh: Especially On Readymade Garment Industry. International Journal Of Scientific \& Technology Research, Vol. 3, Issue 9, September. 